\title{
Produção de novos conhecimentos nas universidades federais e as políticas públicas brasileiras recentes de CT\& $\mathbf{I}^{1}$.
}

\author{
Tulio Chiarini* \\ Márcia Siqueira Rapini ** \\ Karina Pereira Vieira ***
}

\begin{abstract}
Resumo: Este artigo pretende analisar o possível desalinhamento entre as pesquisas científicas e tecnológicas realizadas nas universidades brasileiras com as políticas de CT\&I. O objetivo, portanto, é apresentar as recentes políticas públicas de CT\&I no Brasil e levantar algumas problemáticas dos esforços das pesquisas universitárias e verificar que não há uma coordenação entre as políticas de CT\&I e as pesquisas universitárias. Assim, conforme será demonstrado, apesar do esforço na alocação de recursos financeiros para a investigação em áreas específicas que se enquadram os setores industriais e de prioridade da política científica e tecnológica do país, há uma concentração significativa de recursos humanos (pesquisadores) alocados em outros campos de pesquisa que não são caracterizados como estratégicos para o desenvolvimento do país. É possível refletir que o Brasil pode não estar produzindo quantidade relevante de recursos humanos necessários para competir nos mercados mundiais altamente tecnológicos. Isso é preocupante, uma vez que o país precisa de capital humano qualificado em áreas tecnológicas, para que possa realizar o catch-up com economias mais avançadas.
\end{abstract}

Palavras-chave: Universidades, produção de conhecimento, sistemas de inovação, política educacional.

Código JEL: O33; I23; I28

1 Os pensamentos e ideias expressos neste trabalho não refletem necessariamente aqueles do INT/MCTI nem do IBGE/BH. Os eventuais erros são de inteira responsabilidade dos autores.

\footnotetext{
* Aluno de doutorado em Economia pelo IE/UNICAMP e analista em Ciência e Tecnologia do INT/MCTI.

E-mail: tulio.chiarini@int.gov.br

** Doutora em Economia pelo IE/UFRJ e professora do CEDEPLAR/UFMG.

E-mail: msrapini@cedeplar.ufmg.br

*** Mestre em economia pelo CEDEPLAR/UFMG e analista sócio-econômica do IBGE/BH..

E-mail: karina.pvieira@gmail.com
} 


\section{Introdução}

O processo de desenvolvimento brasileiro apresenta particularidades, no entanto, o país conseguiu se urbanizar de modo relativamente rápido e apresenta um setor industrial da Segunda Revolução Industrial (metalmecânico) completo e avançado, com estrutura de serviços um tanto quanto diversificada. Sem embargo, o Brasil apresenta problemas estruturais que o caracterizam como um capitalismo "ornitorrinco" (Oliveira, 2003), ou seja, além de um setor financeiro atrofiado, problemas de desigualdade e pobreza, possui insuficiente capacidade de transformar conhecimento e ciência em inovação e tecnologia.

O "ornitorrinco" é uma evolução truncada e segue copiando conhecimentos externos, criando uma dependência da produção de novos conhecimentos dos países que já se encontram na Terceira Revolução Industrial (molecular-digital). Enquanto o progresso técnico da Segunda Revolução Industrial permitia relativamente operar por rupturas sem acumulação prévia de conhecimento técnico-científico, por se tratar de conhecimento difuso e universal, o novo conhecimento molecular-digital está "acorrentado" às patentes, ou seja, ele não pode ser encarado como um bem público disponível a todos os atores que queiram utilizá-lo, mas como um bem que pode ser apropriado privadamente. A Terceira Revolução Industrial "borrou" a fronteira entre ciência e tecnologia, amalgamando-as em um único processo, "faz-se ciência fazendo tecnologia e viceversa" (Oliveira, 2003, P.139). Oliveira deixa claro que economias periféricas, como a brasileira, podem apenas copiar o descartável, não a matriz da unidade técnico-científica e a superação dessa fragilidade imporia um esforço de pesquisa científico-tecnológica brutal, aumentando o coeficiente de Pesquisa e Desenvolvimento (P\&D) e Ciência e Tecnologia (C\&T) sobre o PIB ${ }^{2}$. Além disso, conclui que o "ornitorrinco" não possibilita maneiras de avançar, no sentido da acumulação digital-molecular, uma vez que as bases internas de acumulação são insuficientes e estão aquém das necessidades para uma ruptura tecnológica dessa natureza.

Há sérias limitações estruturais que dificultam uma maior inserção científica brasileira em âmbito internacional, porém, acreditamos que políticas públicas de CT\&I devem ser alinhadas, dinamicamente, às instituições de pesquisa em ciência e tecnologia para que o hiato científico-tecnológico seja reduzido. O sentido 'dinâmico' implica uma coordenação de políticas públicas capazes de fomentar pesquisas científicas e tecnológicas voltadas às áreas estratégicas que possam portar ao desenvolvimento.

Um ator relevante no processo de produção de novos conhecimentos é a universidade, entendida aqui como uma instituição cujo papel social vai além de formar uma sociedade mais 'iluminada'. As universidades são uma parte importante do motor capitalista moderno (Nelson, 1990). São responsáveis pelo

2 De acordo com os Indicadores Estatísticos da OECD, em 2009 enquanto o Brasil teve seus dispêndios nacionais em P\&D em relação ao PIB na casa dos 1,19\%, países como Israel (4,27\%), Finlândia (3,96\%), Suécia (3,62\%), Japão (3,44\%), Coréia do Sul (3,36\%), Alemanha (2,82\%), Estados Unidos (2,79\%), OECD (2,34\%) tiveram proporções muito mais significativas. Em relação aos países com relativamente o mesmo nível de desenvolvimento, têm-se as seguintes taxas: China (1,54\%), Rússia (1,24\%), Argentina (0,51\%) e México (0,37\%). Dados em C\&T não são muito confiáveis. 
processo de criação e disseminação, de novos conhecimentos científicos, podendo contribuir para a geração de novas tecnologias, através de pesquisa básica, pesquisa aplicada, desenvolvimento e engenharia. Em suma, a universidade pode ser encarada como um ator estratégico para o catching-up.

Além disso, as universidades são responsáveis por pesquisas de aplicação direta no setor produtivo, gerando ganhos competitivos para as empresas que conseguem transformar o conhecimento científico em inovações tecnológicas em âmbito industrial. O link Universidade-Empresa (subsequentemente abreviado pelo acrônimo U-E) passa a ser relevante para o processo de desenvolvimento econômico.

Este artigo pretende estabelecer uma análise que relacione a produção de C\&T realizada nas universidades federais brasileiras com as políticas públicas de CT\&I a partir de meados dos anos 2000 quando a economia brasileira entra em um novo ciclo de dinamismo, com a recomposição do papel do Estado condutor de um novo padrão de crescimento da economia baseado na expansão do investimento público e privado nos setores industrial e de infraestrutura e nas políticas de inovação

Conforme será demonstrado, apesar do esforço na implementação de políticas públicas em áreas estratégicas específicas que se enquadram os setores industriais e de prioridade, há uma concentração significativa de recursos humanos (pesquisadores) alocados em outros campos de pesquisa que não são caracterizados como estratégicos para o desenvolvimento do país. O artigo está estruturado da maneira que se segue: primeiramente apresenta-se o papel das universidades nos Sistemas de Inovação. Na seção 2, apresenta-se brevemente o sistema universitário brasileiro e as principais políticas recentes no que tange à inovação. Ficará evidente que o governo brasileiro é ciente da importância de fomentar a relação universidade-empresa, no entanto, o país tem formado mais recursos humanos em soft sciences do que em hard sciences, demonstrando que há um desalinhamento das pesquisas científicas e tecnológicas brasileiras e as políticas inovativas. Já na seção 3, busca-se comprovar como as áreas estratégicas definidas pelo governo são estudadas nas universidades. Finalmente, finda-se esse artigo com algumas considerações finais.

\section{Papel das Universidades nos Sistemas de Inovação}

O progresso técnico é essencial para o desenvolvimento econômico, o qual somente ocorre quando há mudanças estruturais significativas na economia. As particularidades do progresso técnico remetem às atividades que o produz - conhecimento científico-tecnológico o qual é um fator competitivo e conditio sine qua non para a capacidade inovativa; é gerado através de um processo dinâmico, resultando da interação entre diferentes atores econômicos. Sua importância para competitividade de empresas e de países vem crescendo na medida em que os novos paradigmas tecnológicos estão permeados, cada vez 
mais, por conhecimentos científicos de fronteira.

Desse modo, constata-se que as Instituições de Ensino Superior (doravante, IES) têm caráter vital não somente na formação de recursos humanos, mas também na geração de conhecimentos técnico-científicos para o desenvolvimento sócio-econômico no contexto dos Sistemas de Inovação. São atores basilares e auxiliam o processo de criação e disseminação, tanto de novos conhecimentos, quanto de novas tecnologias, através de pesquisa básica, pesquisa aplicada e desenvolvimento e, por essa razão, são encaradas como atores estratégicos para o catch-up. De acordo com Nelson (1990) as pesquisas acadêmicas são importantes para a mudança técnica por duas razões distintas: primeiramente por conta da capacitação que fornece aos cientistas e engenheiros que são absorvidos pelo setor industrial e, por conta das pesquisas que são feitas. Ou seja, são importantes ao formar mão-de-obra qualificada e pelos resultados de pesquisas científicas.

A geração de novos conhecimentos nas IES tem se tornado alvo, embora ainda incipiente em países subdesenvolvidos, do interesse de empresas privadas e do próprio setor público, graças ao reconhecimento que um sistema efetivo de pesquisa pública é parte relevante da estrutura institucional necessária para o catch-up (Mazzoleni e Nelson, 2006) e que o sistema educacional tem papel primordial em construir competências e formar as bases do processo inovativo (Lundvall e Christensen, 1999).

A abordagem de Sistema Nacional de Inovação (SNI) permite localizar as especificidades da interação Universidade-Empresa (U-E) em cada país. Esta última faz parte de um importante subconjunto institucional do amplo sistema de troca de conhecimento (Webster,1994). As universidades fazem parte das "Instituições formais Científicas e Técnicas" do SNI (Freeman,1992) e são importantes na construção de competências: educação e treinamento, criação de capital humano, produção e reprodução de técnicas, aprendizado individual (Edquist, 2005).

A relação U-E, em um Sistema de Inovação, fomenta transbordamentos de conhecimento provenientes da pesquisa e desenvolvimento (P\&D), corporificando-se em novos produtos e/ou novos processos. Ademais, Nowotny et al. (2001) sugerem que as IES suscitam a formação e o aprimoramento de profissionais, a partir de treinamentos ao capacitá-los seguindo a demanda de mercado. Entretanto, não se pode negar que são intrincadas as relações e os papéis dos atores envolvidos na produção de conhecimento, além do papel essencial exercido pela própria sociedade na sua absorção (Chiarini; Vieira, 2011). Além disso, em algumas economias, o regime de incentivo para pesquisa é desalinhado: há baixa expectativa que o conhecimento gerado publicamente seja transferido para aplicações de mercado a fim de gerar ganhos de produtividade e competitividade, sem mencionar que grande parte das pesquisas não esta orientada aos resultados (Rodrígues et al., 2008). Essa é uma característica peculiar do sistema de inovação latino-americano e o caso brasileiro não seria uma exceção, o que demonstra que há um gap entre a produção científica e a inovação tecnológica efetiva. Esse desalinhamento é agravado, pois o principal 
locus de produção de conhecimento na América Latina é a universidade (Arocena; Sutz, 2001), sendo que outros institutos (públicos ou privados) contribuem pouco para esse processo, assim, se as universidades ainda são encaradas como instituições inalcançáveis, sem compreender a dinâmica do mercado, a relação universidade-empresa torna-se fraca e a troca de comunicação entre ambas é minimizada, enfraquecida. Os resultados para o desenvolvimento são, portanto, reduzidos.

Estudos mais recentes vêm apontando para mudança relativa no perfil de inovação das empresas brasileiras. Ainda que seja referente a um pequeno grupo, as empresas industriais vêm apresentando crescente aumento da taxa de inovação e da geração de novos produtos e processos, conforme evidenciado nas quatro edições da PINTEC $^{3}$. Consequentemente diversas são as fontes de informação utilizadas pelas empresas para inovar, bem como as relações de cooperação. As universidades e outros centros de ensino superior foram apontados como importante fonte de informação por $13,4 \%$ das empresas inovadoras brasileiras em 2008.

Estudos apontam que ainda que estejam presentes interações de menor complexidade e voltadas para a rotina de produção da empresa, como testes e auxilio no controle da qualidade, há também interações mais complexas que envolvem fluxo bidirecional de conhecimento, como é o caso dos projetos cooperados de P\&D (Rapini et al., 2013; Fernandes et al., 2011; Suzigan et.al., 2009). Por sua vez, a contribuição "indireta" das universidades na formação de pessoal foi apontada como um importante canal para a troca de conhecimento e de informação.

Rapini et al. (2013) demonstram que, ao contrário dos fatos estilizados, as universidades brasileiras fazem mais do que atividades de consultoria e serviços de rotina. Elas também estão envolvidas em projetos de $\mathrm{P} \& \mathrm{D}$ de curto e longo prazo. De acordo com os autores, as interações com as empresas reforçam a missão de formação de recursos humanos das universidades brasileiras e, além disso, elas geram novos conhecimentos. As empresas brasileiras, também estão mudando: estão cada vez mais envolvidas em atividades inovadoras e também em interações mais sofisticadas com as universidades, em busca de conhecimentos codificados e tácitos, em busca de testes e serviços de rotina e também em busca de recursos humanos (Rapini et al., 2013).

Outros trabalhos ainda afirmam que o papel das universidades para o sistema de inovação brasileiro é subestimado (Suzigan; Albuquerque, 2011), pois, contrariamente ao conhecimento convencional, é possível encontrar exemplos na historiografia da ciência e tecnologia que demonstram haver uma relação íntima entre universidades (e institutos de pesquisa) e empresas no cenário brasileiro e a maturação de casos bem sucedidos de interação U-E demandou tempo e foi fruto de um processo de construção institucional de longo prazo. Os exemplos bem sucedidos apontados foram a interação entre a Companhia Siderúrgica Nacional (CSN), a Vale do Rio Doce e o Departamento de Metalurgia e Engenharia de Materiais da Universidade Federal de Minas Gerais (UFMG),

3 No triênio 1998-2000 a taxa média de inovação das empresas brasileiras era 31,5\% passando para 33,1\% entre 20062008. 
o que resultou em bom desempenho para a mineração brasileira e da indústria de aço. Outro exemplo apontado refere-se ao setor aeroespacial, onde a Empresa Brasileira de Aeronáutica (Embraer) se beneficiou da sua proximidade com o Instituto Tecnológico Aeroespacial (ITA) (Suzigan; Albuquerque ; 2011).

\section{Sistema Universitário e Política de Inovação no Brasil}

Essa seção tem duplo propósito: i) realizar a caracterização dos investimentos em educação superior no Brasil, conforme a natureza dos investimentos (público e privado), bem como a formação de pessoal qualificado no ensino superior, segundo áreas de conhecimento, além da produção de conhecimento científico. A fim de enriquecer a análise, observam-se tais características para os países da OECD (Organisation for Economic Cooperation and Development) e alguns países selecionados. O objetivo é identificar características do ensino superior no Brasil que permitam realizar reflexões sobre o papel do Estado brasileiro na formação de recursos humanos altamente qualificados voltados para áreas estratégicas ao desenvolvimento científico e tecnológico do país e também na produção do conhecimento científico. ii) apresentar as evidências recentes sobre as políticas de ciência, tecnologia e inovação (CT\&I) no Brasil, especialmente no que tange o incentivo a pesquisa universitária e a integração com o setor produtivo.

\subsection{Uma comparação do sistema de ensino superior brasileiro}

Historicamente, sabe-se que o Estado teve papel importante na formação do sistema de ensino superior brasileiro. Este é relativamente recente, datando de menos de um século (Mello et al., 2009; Maculan e Mello, 2009). Comparado a outros países da América Latina, o Brasil começou tarde a instituição de universidades (Suzigan e Albuquerque, 2009). Enquanto em alguns países latino-americanos as primeiras universidades foram criadas no século XVI (como no México e no Peru) ou no século XVII (como na Bolívia), no Brasil, faculdades de medicina, direito ou engenharia surgiram apenas no primeiro semestre do Século XIX (Mello et al., 2009) e a primeira universidade foi criada apenas em 1920, no Rio de Janeiro pelo Governo Federal, a Universidade Federal do Rio de Janeiro (UFRJ). Em 1934, o estado de São Paulo criou a sua própria universidade (Maculan e Mello, 2009), a Universidade de São Paulo (USP).

Isso posto, constata-se que o sistema universitário brasileiro teve seu desenvolvimento tardio e que a história econômica do país e da sociedade teve influência duradoura nas instituições de ensino superior (IES), sendo possível citar: concentração em ciências humanas e ciências sociais aplicadas, fraca interação entre as atividades de produção e pesquisa aplicada, circunscrita a alguns campos como a mineração de agronomia/metalurgia e ciências da saúde. Os campi de Engenharia germinaram mais tarde, no Brasil, e, nos cursos graduação, a ligação entre o ensino e atividades de pesquisa passou 
a ser conduzida apenas em 1960 alimentada pelo governo federal (Suzigan e Albuquerque, 2009).

As IES brasileiras passaram a se proliferar significativamente a partir da segunda metade da década de 90, quando se observou altas taxas de crescimento marcado principalmente pela expansão do número de instituições privadas. Entre 2004 e 2009, houve expansão do número de matrículas nos cursos de graduação no ensino superior, que passou de 4,2 milhões para 5,9 milhões, crescendo a uma taxa média de 7,14\% ao ano. Em 2008, o mercado brasileiro de ensino superior já era o maior da América Latina e o quarto maior do mundo, com 5,958 milhões de matrículas. (UNESCO, 2010)

Segundo a OECD, 11\% da população brasileira entre 25 e 34 anos completou o ensino superior, em 2008. Em países da OECD, este número chega a $35 \%$ da população jovem. No Japão e na Coréia, 50\% da população da mesma faixa etária concluíram o ensino terciário. (OECD, 2010).

O Brasil não dispõe de estatísticas que mensurem o investimento privado em educação superior. No que se refere aos investimentos feitos pelo setor público, estes representam $0,8 \%$ do PIB brasileiro. Nos países da OECD, os investimentos em educação superior representam em média 1,5\% do PIB. Os maiores investimentos em relação ao PIB são observados em países como: Estados Unidos (3,1\%), Canadá (2,6\%), Coréia $(2,4 \%)$ e Chile $(2,0 \%)$. (OECD, 2010b).

Quando se observa os investimentos em educação superior, nota-se que, nos países da OECD, eles se caracterizam pela forte presença do investimento público (1,0\% do PIB) vis-à-vis o privado (0,5\% do PIB), com destaque para França, Alemanha e os países nórdicos. O modelo norte-americano difere do observado para os países da OECD como um todo. Nos Estados Unidos, os investimentos públicos em educação superior representam 1,0\% do PIB, enquanto os investimentos privados representam 2,1\%. (OECD, 2010). Dessa forma, verifica-se que o Brasil investe pouco em educação superior $(0,8 \%$ do PIB) e esse investimento está pulverizado em várias áreas do conhecimento e não privilegia áreas estratégicas para o desenvolvimento do país, como será visto adiante.

Quanto à demanda dos estudantes por cursos superiores, segundo o Ministério da Educação e Cultura (MEC), em 2009, os cursos com maior número de matrículas, nas IES brasileiras, foram Administração (18\%), Direito (11\%) e Pedagogia (10\%). Os cursos de Engenharia representaram 7\% do total de matrículas no mesmo ano. A preferência por cursos da área de Ciências Humanas e Sociais Aplicadas não é uma característica restrita ao Brasil. Em países da OCDE, 62,3\% dos concluintes no ensino superior são em cursos de Humanas, Sociais Aplicadas, Letras e Artes, e Educação. Nos Estados Unidos, 73,3\% dos concluintes são nestas áreas de conhecimento. (TAB. 1). 
Tabela 1: Concluintes no ensino superior (\%), por área, países selecionados, 2008

\begin{tabular}{|c|c|c|c|c|c|c|c|}
\hline & $\begin{array}{c}\text { Engenha- } \\
\text { ria }\end{array}$ & Saúde & $\begin{array}{l}\text { Ciências } \\
\text { Biológi- } \\
\text { cas, Física } \\
\text { e Ciências } \\
\text { Agrárias }\end{array}$ & $\begin{array}{c}\text { Mate- } \\
\text { mática e } \\
\text { Ciência } \\
\text { da Com- } \\
\text { putação }\end{array}$ & $\begin{array}{l}\text { Humanas, } \\
\text { Soc. } \\
\text { Aplicadas, } \\
\text { Letras, } \\
\text { Artes, } \\
\text { Educação }\end{array}$ & $\begin{array}{c}\text { Não } \\
\text { especifi- } \\
\text { cado }\end{array}$ & Total \\
\hline $\begin{array}{l}\text { Coréia do } \\
\text { Sul }\end{array}$ & 23,2 & 9,2 & 6,2 & 4,9 & 56,4 & - & 100 \\
\hline Portugal & 18,3 & 17,6 & 7,9 & 7,2 & 48,9 & - & 100 \\
\hline Rússia & 17,9 & 4,1 & 5,1 & 4,5 & 68,5 & - & 100 \\
\hline Indonésia & 16,5 & 6,0 & 8,4 & 3,6 & 59,8 & 5,7 & 100 \\
\hline Suécia & 16,2 & 26,0 & 4,8 & 2,7 & 50,1 & - & 100 \\
\hline Finlândia & 15,1 & 15,1 & 7,6 & 6,3 & 55,8 & - & 100 \\
\hline Itália & 15,1 & 15,1 & 6,7 & 2,1 & 59,7 & 1,3 & 100 \\
\hline Espanha & 14,3 & 15,8 & 6,9 & 5,3 & 57,4 & 0,3 & 100 \\
\hline México & 14,2 & 9,5 & 4,8 & 7,5 & 63,2 & 0,8 & 100 \\
\hline Chile & 13,7 & 14,5 & 5,4 & 2,3 & 64,1 & - & 100 \\
\hline Áustria & 13,6 & 9,6 & 6,7 & 7,8 & 62,0 & 0,1 & 100 \\
\hline França & 13,4 & 9,9 & 8,5 & 6,0 & 62,3 & - & 100 \\
\hline Bélgica & 12,8 & 15,6 & 7,9 & 3,0 & 58,9 & 1,9 & 100 \\
\hline Alemanha & 12,4 & 9,3 & 10,0 & 7,9 & 60,1 & 0,2 & 100 \\
\hline Grécia & 12,2 & 8,1 & 8,5 & 8,2 & 63,0 & - & 100 \\
\hline $\begin{array}{l}\text { OECD } \\
\text { (média) }\end{array}$ & 12,0 & 13,5 & 7,0 & 4,8 & 62,3 & 0,6 & 100 \\
\hline Dinamarca & 11,7 & 26,1 & 4,9 & 4,1 & 53,2 & - & 100 \\
\hline Suíça & 11,6 & 10,5 & 9,3 & 3,6 & 64,3 & 0,6 & 100 \\
\hline Israel & 10,0 & 9,3 & 7,2 & 3,9 & 69,6 & - & 100 \\
\hline Turquia & 9,4 & 6,5 & 7,9 & 3,4 & 72,8 & - & 100 \\
\hline $\begin{array}{l}\text { Reino } \\
\text { Unido }\end{array}$ & 9,0 & 13,6 & 8,6 & 5,8 & 62,0 & 1,0 & 100 \\
\hline Canadá & 8,4 & 10,1 & 10,3 & 3,7 & 64,1 & 3,3 & 100 \\
\hline Noruega & 7,8 & 23,7 & 3,7 & 4,9 & 59,9 & 0,2 & 100 \\
\hline Holanda & 7,7 & 18,2 & 3,1 & 4,2 & 66,4 & 0,4 & 100 \\
\hline EUA & 6,1 & 10,8 & 6,4 & 3,4 & 73,3 & - & 100 \\
\hline Brasil & 4,6 & 15,6 & 4,9 & 2,7 & 66,4 & 5,8 & 100 \\
\hline
\end{tabular}

Fonte: Elaboração própria a partir de dados da OCDE (2010).

A diferença entre o Brasil e os países desenvolvidos, no que tange às conclusões do ensino superior por área de conhecimento, é identificada principalmente na área de Engenharia (TAB. 1). Apenas 4,6\% dos concluintes no ensino superior brasileiro são em cursos de engenharia. Nos países da OCDE, esta área de conhecimento concentra $12,2 \%$, enquanto que na Coréia do Sul chega a 23,2\% ${ }^{4}$. Nota-se ainda que em todos os países apresentados na TAB. 4 Vale ressaltar que nos EUA apenas 6,1\% dos concluintes são dos cursos de engenharia, no entanto, devido à falta de informações sobre a quantidade absoluta de formandos, essa análise fica um pouco prejudicada. Embora a OCDE não disponha de dados recentes para a Índia, sabe-se que, entre 2002 e 2003, as graduações em cursos de engenharia representavam $7,5 \%$ do total no país. Disciplinas caracterizadas como Ciências representavam $19,8 \%$ das matrículas, e Artes e Negócios representavam 62\% do total. Em 2002, as instituições de ensino superior, na Índia, denominadas 
1, o percentual de concluintes em Humanas, Sociais Aplicadas, Letras e Artes, Educação é o maior vis-à-vis as demais áreas de conhecimento. Não se está aqui dizendo que o percentual brasileiro é inadequado, o que se sugere aqui é que o percentual brasileiro de engenheiros, mesmo sendo baixo, pode não ser de qualidade e não ser capaz de suprir as necessidades inovativas do país.

A observação da natureza dos investimentos (públicos ou privados) em educação superior, bem como dos estudantes matriculados, segundo a área de conhecimento, é importante para que se possa caracterizar a formação de mão-deobra qualificada, no país. No caso brasileiro, é possível fazer duas afirmações: i) o setor público tem papel importante na oferta de ensino superior; ii) a formação de mão-de-obra qualificada apresenta alta concentração nas áreas de Humanas e Sociais Aplicadas.

No que se refere à produção de conhecimento, uma forma adequada de mensurá-la é através das publicações de artigos científicos em periódicos indexados. Examinando o número de artigos científicos em algumas áreas de conhecimento bastante específicas, ou seja, física, biologia, química, matemática, medicina, pesquisa biomédica, engenharia e ciências da terra, e tecnologia espacial, o Brasil está ranqueado na $15^{\mathrm{a}}$ posição mundial, contribuindo com $1,59 \%$ de todos os artigos publicados ${ }^{5}$. Isso demonstra o desempenho modesto do país referente as economias industrializadas (FIG. 1) e o pior desempenho em relação aos outros países do BRIC: a China contribuiu com 7,62\%, a Índia com $2,44 \%$ e a Rússia com $1,87 \%$ da produção mundial de artigos nas áreas mencionadas, enquanto que economias menores que a brasileira, como é o caso da Itália e Espanha, contribuíram com 3,56\% e 2,81\%, respectivamente.

Mesmo com esse desempenho modesto, considerando que o Brasil possui um Sistema de Inovação imaturo (Albuquerque et al., 2005; Suzigan e Albuquerque, 2008), caracterizado por fracas ligações entre infra-estrutura científica e as atividades tecnológicas (Albuquerque, 2004), as atividades científicas do país são impressionantes, já que o investimento e a produtividade científica superam as tendências gerais de crescimento, tornando o país uma nova nação científica emergente (RS, 2011). No entanto, vale ressaltar que esse título concedido ao país, não significa que tenha superado os problemas estruturais normalmente associados às economias latino-americanos, como o analfabetismo e a dependência tecnológica, por exemplo.

Uma particularidade do sistema universitário brasileiro é que as IES privadas são dedicadas principalmente ao ensino em algumas áreas bem definidas do conhecimento (tais como gestão, direito, ciências humanas), com as sua atividade de pesquisa sendo quase inteiramente residual (Maculan e Mello, 2009). Esta informação é corroborada, levando em conta o número de artigos publicados em revistas indexadas nacional e internacionalmente: universidades

\footnotetext{
Colleges, totalizavam 15.437, dos quais 6,9\% eram de Engenharia/Tecnologia e 8,1\% eram da área de Saúde. (Kapur e Mehta, 2004).

5 Dados do World Bank Data Catalog. Nota: A produção científica aqui se refere aos artigos científicos e artigos de engenharia publicados nos seguintes campos de conhecimento: física, biologia, matemática, química, medicina, biomedicina, engenharia e tecnologia, ciências da terra e ciências espaciais.
} 
brasileiras financiadas pelo governo federal contribuem para $45 \%$ do total de publicações de artigos, em 2008, e se forem somadas a essas as publicações das três universidades financiadas pelo estado de São Paulo - Universidade Estadual de Campinas (UNICAMP), Universidade de São Paulo (USP) e Universidade Estadual Paulista (UNESP) - a porcentagem salta para $66 \%$.

De acordo com Gusso e Nascimento (2011) a facilidade de proliferação das IES acarretou o obscurecimento de funções e competências institucionais que têm a ver com o nível de complexidade da formação educativa, com os seus padrões de qualidade, de inserção nos sistemas de produção e de disseminação de ciência e tecnologia. Dessa forma, o princípio legislativo de "indissociabilidade de ensino e pesquisa" acabou sendo acomodado por conveniências políticas, bem como o princípio da "autonomia acadêmica", no sentido de liberdade de criar cursos e vagas ${ }^{6}$. Assim, a inserção dos concluintes das IES brasileiras na economia pode não estar contribuindo de forma qualitativa para o quadro técnico-centífico de que o país necessita, o que dificulta a formação de agentes de inovação capazes de conectar a produção de conhecimento científico com o avanço das capacidades tecnológicas e competitivas do sistema produtivo (Gusso e Nascimento, 2011).

De acordo com o MEC em 2009, havia 186 universidades brasileiras, dos quais aproximadamente 53\% eram públicas (federal, estadual ou municipal) e cerca de $47 \%$ eram privadas. No entanto, se todas as instituições de ensino superior (universidades, centros universitários e faculdades) são consideradas, havia 2.314 instituições, das quais cerca de 10\% eram públicas. Em 2010, mais três universidades federais foram legitimadas e estabelecidas, o que representa um total de 58 universidades financiadas pelo governo federal, que são desigualmente distribuídas pelo território nacional ${ }^{7}: 33 \%$ das universidades estão concentradas na região Sudeste, enquanto apenas 9\% estão na região Centro-Oeste.

A proposta que se apresenta neste trabalho é a de uma integração entre as políticas educacionais para o ensino superior e as políticas de Ciência, Tecnologia e Inovação (CT\&I) brasileiras. Há evidências empíricas, a serem apresentadas na seção 3 , de que apesar do esforço realizado em políticas de CT\&I que definem áreas estratégicas para o país, existe claramente uma distorção na formação de recursos humanos (pesquisadores) voltados para tais áreas, conforme será descrito na seção 3.

Isto é corroborado por recente informação da PINTEC (2008), conforme pode ser visualizado na TAB. 2. Pela primeira vez, desde a primeira edição da pesquisa em 2000, a falta de pessoal qualificado apareceu em terceiro

\footnotetext{
6 A literatura de educação superior tem uma importante contribuição em relação a este tópico. Clark (2008), apud Kruss (2011), distingue dois diferentes tipos de crescimento das instituições de educação superior. Um seria o crescimento à partir da fragmentação das disciplinas, sendo um crescimento complexo e substantivo, que é liderado pela geração de conhecimento e de pesquisa. Outro seria um "crescimento reativo" motivado pelo aumento de estudantes ou pela demanda do mercado de trabalho, estando relacionado à massificação da educação superior.

7 De acordo com o MEC, outras quatro universidades federais serão criadas nos próximos anos: Universidade Federal do Sul e Sudeste do Pará, Universidade Federal da Região do Cariri, Universidade Federal do Oeste da Bahia e Universidade Federal do Sul da Bahia.
} 
lugar dentre obstáculos e dificuldades para a inovação. Até então este fator configurava em quarto lugar, depois da escassez de fontes apropriadas de financiamento ${ }^{8}$. Ainda é preciso investigar melhor este resultado da PINTEC, mas uma das possíveis explicações é que realmente as universidades/IES não estão conseguindo formar pessoal com qualificação adequada às exigências da indústria, o que é uma reclamação freqüente da Confederação Nacional das Indústrias (CNI), e as analises subseqüentes do artigo irão buscar explicar em parte as razões para este desalinho ${ }^{9}$.

Tabela 2: Obstáculos à inovação das empresas inovadoras, PINTEC, 2000 a 2008.

\begin{tabular}{|c|c|c|c|c|}
\hline Fatores & $1998-2000$ & 2001-2003 & 2003-2005 & 2006-2008 \\
\hline Riscos econômicos excessivos & 76,4 & 74,5 & 73,1 & 65,6 \\
\hline Elevados custos da inovação & 82,8 & 79,6 & 76,2 & 73,1 \\
\hline $\begin{array}{l}\text { Escassez de fontes } \\
\text { apropriadas de } \\
\text { financiamento }\end{array}$ & 62,1 & 56,6 & 57,7 & 51,4 \\
\hline Rigidez organizacional & 21,2 & 17,8 & 26 & 31,4 \\
\hline Falta de pessoal qualificado & 45,6 & 47,4 & 47 & 58,8 \\
\hline $\begin{array}{l}\text { Falta de informação sobre } \\
\text { tecnologia }\end{array}$ & 35,6 & 35,8 & 32,8 & 36,7 \\
\hline $\begin{array}{l}\text { Falta de informação sobre } \\
\text { mercados }\end{array}$ & 33,9 & 30,4 & 31,1 & 32,5 \\
\hline $\begin{array}{l}\text { Escassas possibilidades de } \\
\text { coop. com outras empresas/ } \\
\text { instituições }\end{array}$ & 32,2 & 29,5 & 28,3 & 31,6 \\
\hline $\begin{array}{l}\text { Dificuldade para se adequar } \\
\text { a padrões, normas e } \\
\text { regulamentações }\end{array}$ & 25,1 & 32,9 & 32,2 & 32,4 \\
\hline $\begin{array}{l}\text { Fraca resposta dos } \\
\text { consumidores quanto a } \\
\text { novos produtos }\end{array}$ & 25,6 & 23,9 & 27,9 & 29,9 \\
\hline $\begin{array}{l}\text { Escassez de serviços técnicos } \\
\text { externos adequados }\end{array}$ & 26,2 & 25,6 & 33,7 & 37,6 \\
\hline $\begin{array}{l}\text { Centralização da atividade } \\
\text { inovativa em outra emp. do } \\
\text { grupo }\end{array}$ & ND & 1 & 1,3 & 1,9 \\
\hline Total & 12.411 & 12.732 & 11.551 & 100 \\
\hline
\end{tabular}

Fonte: Elaboração própria a partir da PINTEC/IBGE.

\subsection{Políticas de CT\&I no Brasil: as evidências mais recentes}

O período de 1995-2002 foi marcado por ações esparsas no que se refere à política de inovação, com a ressalva da criação, pelo Ministério da Ciência, Tecnologia e Inovação (MCTI), dos Fundos Setoriais e também da proposta

\footnotetext{
8 Os diversos programas do governo federal de fomento e financiamento à inovação através da Financiadora de Estudos e Projetos (FINEP) e Banco Nacional de Desenvolvimento Econômico e Social (BNDES) parecem estar surtindo efeito na redução do gap do financiamento.

9 Outra explicação seria deficiências interna da empresa que não consegue remunerar e/ou valorizar os profissionais existentes, refletindo em "aparente" falta de pessoal qualificado.
} 
da Lei de Inovação (Koeller, 2007). Nesse período, iniciou-se a articulação de uma proposta para a possível criação de uma política de inovação, cujo objetivo era de propiciar estímulo às inovações tecnológicas através da modernização do ambiente regulatório, da integração do país na capacitação voltada para a inovação e da visão da Política de Ciência e Tecnologia como estratégica ao desenvolvimento.

Iniciativas deste período voltadas ao fomento da interação U-E são os Programas Alfa e Ômega ${ }^{10}$ do MCTI, voltados para o apoio às Pequenas e Médias Empresas (PMEs). Na mesma direção o III Programa de Apoio à Capacitação Tecnológica (PACTI), iniciado em 1998, teve como objetivo a difusão e a transferência de tecnologia do setor acadêmico para o setor industrial. Pela primeira vez, foram lançados editais que condicionavam o fomento do projeto à cooperação entre empresas e universidades/institutos de pesquisa. As empresas deveriam participar com uma contrapartida dos recursos (que poderia variar de $10 \%$ a $50 \%$ do total do projeto).

Aqui vale destacar também a Lei 10.168/2000, que instituiu o "Programa de Estímulo à Interação Universidade-Empresa para o Apoio à Inovação", a fim de incentivar a interação das universidades e centros de pesquisa com o setor produtivo, em prol do desenvolvimento do país. Os fundos setoriais voltados para ciência e tecnologia, no Brasil, foram criados com a função de financiar atividades ligadas à ciência e tecnologia $(\mathrm{C} \& \mathrm{~T})$ dos mais diversos setores da indústria nacional sempre com foco no estímulo ao desenvolvimento de pesquisa científica e tecnológica pelo setor produtivo. O primeiro fundo setorial criado foi para o setor de Petróleo e Gás Natural, em 1997.

A partir de então começou a ser elaborada uma "Estratégia de Generalização de Outros Fundos Setoriais" com os seguintes objetivos: prover recursos para atividades de C\&T dos setores industriais; criar um Comitê Gestor com a função de conciliar interesses de empresários, governos e cientistas; buscar relações de sinergia entre políticas voltadas para o desenvolvimento industrial e para o desenvolvimento tecnológico. (Pacheco, 2003). Entre 1997 e 2002 foram criados mais 13 fundos. Dentre estes, destaca-se o Fundo Verde-Amarelo, de natureza mais sistêmica, que visa incentivar a interação entre universidades e empresas no desenvolvimento científico e tecnológico brasileiro ${ }^{11}$. No âmbito deste fundo vem sendo criados diversos mecanismos de fomento à interação universidade-empresa como editais de fomento a projetos cooperados entre empresas e universidades/ institutos de pesquisa; apoio à consolidação de incubadoras; programas para a capacitação de mão-de-obra (Programa de Formação de Recursos Humanos em Áreas Estratégicas - RHAE) e fomento ao capital de risco.

\footnotetext{
10 O Programa Alfa fornecia financiamento não-reembolsável para PMEs (até 100 empregados) para o custeio de estudos de viabilidade técnica e econômica de projetos de desenvolvimento de inovações tecnológicas. O Projeto Ômega custeava até $50 \%$ dos dispêndios totais de projetos cooperativos de empresas com universidades ou centros de pesquisa, sendo recursos não-reembolsáveis (de até $\mathrm{R} \$ 200.000,00$ ).

11 O fundo é financiado com 50\% da Contribuição de Intervenção no Domínio Econômico - CIDE, cuja arrecadação advém da incidência de alíquota de $10 \%$ sobre a remessa de recursos ao exterior para pagamento de assistência técnica, royalties, serviços técnicos especializados ou profissionais; $43 \%$ da receita estimada do IPI incidente sobre os bens e produtos beneficiados pelos incentivos fiscais da Lei de Informática.
} 
Tais ações se revelaram importantes para o estabelecimento de diretrizes e estratégias para o desenvolvimento de uma Política de CT\&I moderna e consistente com as necessidades do país e integrada à Política Econômica.

A partir de 2003, com a descontinuidade da política do governo Lula com diferentes projetos de investimento efetuados, com orientação desenvolvimentista, envolvendo políticas de dinamismo do mercado interno, apoiando, assim, o setor privado e investimentos do setor de infraestrutura, políticas sociais e políticas de crédito. Além disso, o novo governo passou a dar importância à inovação com maior amplitude. Houve a criação da Política Nacional de Ciência, Tecnologia e Inovação, e da Política Industrial Tecnológica e de Comércio Exterior (PITCE). Conforme, Koeller (2007), a PITCE preservou os objetivos definidos no período anterior, ou seja, a dinâmica da inovação e a difusão de tecnologias foram entendidas como facilitadores da disputa e da conquista de novos mercados e, para tanto, políticas públicas foram equacionadas tendo como objetivo o aumento da eficiência econômica e do desenvolvimento e da difusão de tecnologias.

A PITCE confere a certas áreas o status de 'portadoras de futuro' e 'opções estratégicas' e visa orientar a ação pública na busca de vantagens comparativas dinâmicas e aumento de produtividade (Campanário et al., 2005). As áreas estratégicas são definidas pela PITCE (2003) considerando-se que: “a) apresentam dinamismo crescente e sustentável; b) são responsáveis por parcelas expressivas dos investimentos internacionais em Pesquisa e Desenvolvimento; c) abrem novas oportunidades de negócios; d) relacionam-se diretamente com a inovação de processos, produtos e formas de uso; e) promovem o adensamento do tecido produtivo, e f) são importantes para o futuro do país e apresentam potencial para o desenvolvimento de vantagens comparativas dinâmicas." (PITCE, 2003, p.16).

Enquadram-se nesses requisitos as seguintes áreas: software, fármacos, biotecnologia, biomassa, nanotecnologia, semicondutores e bens de capital. Tais áreas podem ser articuladas em dois eixos de atuação ${ }^{12}$ conforme a PITCE: 1) opções estratégicas: semicondutores, software, bens de capital e fármacos; 2) atividades portadoras de futuro: biotecnologia, nanotecnologia e biomassa, as quais têm o potencial de mudar radicalmente processos/produtos (Salerno, 2004).

Em 2004, foi adotado um novo modelo de gestão dos fundos setoriais que tornou mais ampla e mais eficiente a aplicação dos recursos do Fundo Nacional de Desenvolvimento Científico e Tecnológico (FNDCT) nos setores prioritários da PITCE.

Entre as ações regulatórias de incentivo à inovação, a partir de 2003, é possível destacar a aprovação da Lei da Inovação, a Lei do Bem e a regulamentação do FNDCT.

A Lei 10.973/04, conhecida como Lei da Inovação, foi regulamentada em outubro de 2005 (Decreto n. 5.563, de 11/10/2005). Além do forte incentivo à

12 Existe um terceiro eixo de atuação da PITCE que não está no escopo de análise desse estudo: linhas de ação horizontais: inovação e desenvolvimento tecnológico, inserção externa, modernização industrial e melhoria do ambiente institucional/ampliação da capacidade e escala produtiva. 
interação da pesquisa científica com o setor produtivo, a Lei de Inovação instituiu o apoio à inovação sob a forma de subvenção, pela primeira vez no Brasil. A Lei 11.196/05, conhecida como Lei do Bem, foi regulamentada, em novembro de 2005, a fim de apoiar a inovação e a pesquisa científica e tecnológica através de subvenção econômica à remuneração de pesquisadores (mestres e doutores) que tenham vínculo empregatício com empresas presentes no Brasil.

Em abril de 2007, o então presidente Lula aprovou duas medidas, que foram encaminhadas ao congresso, com o objetivo de acelerar as políticas de $\mathrm{C} \& \mathrm{~T}$, no Brasil, bem como garantir a ampliação e a efetividade da aplicação dos recursos destinados à C\&T. Tais medidas constituem da regulamentação do FNDCT e do funcionamento e composição do Conselho Nacional de Ciência e Tecnologia. Ao final de 2007, o Congresso Nacional aprovou a regulamentação do FNDCT, através da Lei 11.540, possibilitando a ação integrada dos fundos setoriais, potencializando as ações do MCTI.

A PITCE não foi uma política muito clara e sofreu fortes críticas (Almeida, M., 2011) e em 2008 foi criada a Política de Desenvolvimento Produtivo (PDP) cujo objetivo era dar sustentabilidade ao ciclo de expansão da economia brasileira com programas estruturantes para sistemas produtivos, orientados por objetivos estratégicos. De acordo com Almeida M. (2011) a PDP apresentou como contradição as metas curto prazistas, coincidentes com o ciclo eleitoreiro.

Essa é a grande inconsistência temporal das políticas industriais adotadas por governos democráticos: a mudança estrutural que se deseja com a política industrial é, necessariamente, uma política de longo prazo, mas os governos precisam mostrar resultados no curto prazo para que sejam premiados pelo "sucesso" dessas políticas e possam continuar com a sua implementação. (Almeida, M., 2011, p. 75).

O Plano Brasil Maior (PBM), lançado em 2011 pelo governo Dilma Rousseff, continuou o planejamento econômico do governo Lula (PITCE e PDP), a fim de sustentar o crescimento econômico no Brasil, com foco em inovação e expansão industrial brasileira por meio de medidas como isenções para investimento produtivo e das exportações, expansão do crédito e melhoria regulamentar da inovação. De acordo com Almeida J. (2011) o PBM demonstra que o governo deu à indústria um papel importante na promoção do desenvolvimento do país e suas forças estão ligadas ao pioneirismo de algumas ações como a redução de impostos sobre investimentos e exportações, e a significativa contribuição da FINEP (Financiadora de Estudos e Projetos) e BNDES (Banco Nacional de Desenvolvimento Econômico e Social) de financiamento para o investimento e a inovação. No entanto, Almeida J. (2011, p. 12) nota que, mesmo com as medidas propostas pelo PBM, "o Brasil ainda está longe de ser um país facilitador e promotor do investimento à inovação e à exportação" e com essas medidas ainda é pouco provável que o país venha a se tornar mais autônomo em termos tecnológicos. 


\section{3 Áreas Estratégicas e Áreas do Conhecimento}

Para fins desse estudo, tanto as opções estratégicas quanto as atividades portadoras de futuro propostas pela PITCE são tratadas como 'áreas estratégicas' lato sensu. Já, por áreas de conhecimento, referimo-nos às áreas ou disciplinas em que o conhecimento é geralmente classificado de acordo com as categorias propostas pela Coordenação de Aperfeiçoamento de Pessoal de Nível Superior (CAPES). Foram identificadas as seguintes áreas de conhecimento: Ciências Agrárias; Ciências Biológicas; Ciências Exatas e da Terra; Ciências da Saúde; Ciências Humanas; Sociais Aplicadas; Engenharias; Linguística, Letras e Artes.

Seguindo o cruzamento das áreas estratégicas lato sensu da PITCE, com as grandes áreas de conhecimento adotadas pela CAPES, proposto por Chiarini e Vieira (2011), chegou-se ao Quadro $1^{13}$.

Quadro 1: Áreas do conhecimento versus setores estratégicos da PITCE

\begin{tabular}{|c|c|c|c|c|}
\hline Fatores & 1998-2000 & 2001-2003 & 2003-2005 & 2006-2008 \\
\hline Riscos econômicos excessivos & 76,4 & 74,5 & 73,1 & 65,6 \\
\hline Elevados custos da inovação & 82,8 & 79,6 & 76,2 & 73,1 \\
\hline $\begin{array}{l}\text { Escassez de fontes apropriadas de } \\
\text { financiamento }\end{array}$ & 62,1 & 56,6 & 57,7 & 51,4 \\
\hline Rigidez organizacional & 21,2 & 17,8 & 26 & 31,4 \\
\hline Falta de pessoal qualificado & 45,6 & 47,4 & 47 & 58,8 \\
\hline Falta de informação sobre tecnologia & 35,6 & 35,8 & 32,8 & 36,7 \\
\hline Falta de informação sobre mercados & 33,9 & 30,4 & 31,1 & 32,5 \\
\hline $\begin{array}{l}\text { Escassas possibilidades de coop. com } \\
\text { outras empresas/ instituições }\end{array}$ & 32,2 & 29,5 & 28,3 & 31,6 \\
\hline $\begin{array}{l}\text { Dificuldade para se adequar a padrões, } \\
\text { normas e regulamentações }\end{array}$ & 25,1 & 32,9 & 32,2 & 32,4 \\
\hline $\begin{array}{l}\text { Fraca resposta dos consumidores } \\
\text { quanto a novos produtos }\end{array}$ & 25,6 & 23,9 & 27,9 & 29,9 \\
\hline $\begin{array}{l}\text { Escassez de serviços técnicos externos } \\
\text { adequados }\end{array}$ & 26,2 & 25,6 & 33,7 & 37,6 \\
\hline $\begin{array}{l}\text { Centralização da atividade inovativa } \\
\text { em outra emp. do grupo }\end{array}$ & ND & 1 & 1,3 & 1,9 \\
\hline Total & 12.411 & 12.732 & 11.551 & 100 \\
\hline
\end{tabular}

Fonte: Chiarini e Vieira (2011).

Com base nessas áreas estratégicas lato sensu e as áreas do conhecimento da CAPES, pode-se notar que as Ciências Sociais Aplicadas, Ciências Humanas e Linguistica, Letras e Artes não são contempladas como áreas estratégicas relevantes para o desenvolvimento industrial e científico-tecnológico do Brasil. No entanto, não se busca afirmar que elas não sejam importantes para 13 Entretanto, vale lembrar que, apesar de haver uma correlação entre as áreas de conhecimento (CAPES) e os setores estratégicos para o desenvolvimento (PITCE), nada garante que a pesquisa em uma área definida como estratégica seja conduzida por pesquisadores de áreas do conhecimento que não estejam diretamente associadas à mesma. Chiarini e Vieira (2011) mostram, por exemplo, que, apesar de software pertencer à área de conhecimento Ciências Exatas e da Terra, há pesquisas relacionadas a software em outros campos de pesquisa, como Ciências Agrárias, Engenharia, Ciências da Saúde, Ciências Sociais, Humanas e até mesmo em Linguística, Letras e Artes; o mesmo acontece em pesquisas relacionadas a outros setores estratégicos. 
compreensão da dinâmica regional, histórica, econômica e social; reconhecemos o papel dessas áreas; não é a intenção deste artigo defender a exclusão de linhas de pesquisa que não estejam direcionadas para os setores prioritários às políticas industriais e científico-tecnológicas do país. Dito isto, busca-se enfatizar a importância de um maior foco sobre as pesquisas desenvolvidas pelas IES em áreas prioritárias ao desenvolvimento científico e tecnológico, uma vez que esta visão vai de encontro com os temas de Sistemas de Inovação e é apoiada pela experiência de países que incentivaram formação acadêmica em ciência e tecnologia. Um bom exemplo é o caso da Índia que tem estimulado a formação de pessoal qualificado em ciência e tecnologia com ênfase em áreas como Ciências Exatas e Engenharia.

Uma primeira tentativa de atualizar o Quadro 1 acrescentando apenas duas das cinco diretrizes estruturantes definidas pelo Plano Brasil Maior, apresentada no Quadro 2. Optou-se por cruzar às áreas do conhecimento somente as diretrizes estruturantes referentes à ampliação e criação de novas competências tecnológicas e de negócios (bens de capital, tecnologias da informação e comunicação, química e petroquímica, aeronáutica e espacial, complexo de defesa; e complexo industrial da saúde) e ao desenvolvimento das cadeias de suprimento em energias (petróleo e gás, bioetanol, energias renováveis).

Quadro 2: Grandes áreas de conhecimento versus áreas do Brasil Maior.

\begin{tabular}{lc}
\hline $\begin{array}{c}\text { Áreas do conhecimento } \\
\text { CAPES }\end{array}$ & $\begin{array}{c}\text { Áreas estruturantes } \\
\text { Plano Brasil Maior }\end{array}$ \\
\hline Ciências Exatas e da Terra & $\begin{array}{c}\text { Tecnologia da informação } \\
\text { Química }\end{array}$ \\
\hline Engenharias & $\begin{array}{c}\text { Aeronáutica e espacial } \\
\text { Bens de capital } \\
\text { Comunicação } \\
\text { Energia }\end{array}$ \\
\hline Ciências da Saúde & $\begin{array}{c}\text { Equipamentos de Saúde } \\
\text { Petroquímica }\end{array}$ \\
\hline Ciências Agrárias & Fármacos \\
\hline Ciências Biológicas & - \\
\hline Ciências Sociais aplicadas & - \\
\hline Ciências Humanas & - \\
\hline Lingüística, Letras e Artes & - \\
\hline Multidisciplinar & - \\
\hline Eonte: Elaboraça prôpria & - \\
\hline
\end{tabular}

Fonte: Elaboração própria.

Nota: vale ressaltar que embora haja um cruzamento direto entre áreas do conhecimento (CAPES) e áreas estruturantes do Plano Brasil Maior, nada impede que pesquisas sobre determinada área estratégica sejam realizadas por pesquisadores de outras áreas do conhecimento. Por exemplo, embora a área estruturante energia renovável' pertença às Engenharias, no entanto, pesquisas sobre energia renovável são realizadas por demais áreas, como Agrárias (biomassa). 
Ficou evidenciado o destaque às áreas de engenharias, sobretudo Engenharia Química, Engenharia Mecânica, Engenharia Aeroespacial, Engenharia Elétrica e Eletrônica, Engenharia Biomédica, Engenharia de Telecomunicações, Engenharia de Materiais, etc., essenciais para as áreas estruturantes definidas pelo plano Brasil Maior. No entanto, ao se analisar o potencial científico nas principais grande áreas (Ciências Exatas e da Terra, Engenharias e Saúde) à partir do número de pesquisadores a da produção (artigos), tem-se que 40\% dos pesquisadores vinculados aos Grupos de Pesquisa do CNPq pertencem a essas áreas, sendo 10\% pertencentes às Ciências Exatas e da Terra, 12\% às Engenharias e 17\% às Ciências da Saúde (TAB. 3). Em termos de produção estas áreas foram responsáveis, respectivamente, por 13\%, 9\% e 25\% do total de artigos publicados em periódicos indexados nacionais e internacionais (totalizando 47\% do total).

Tabela 3: Total de pesquisadores, pesquisadores doutores, total artigo, por grande área do conhecimento, Brasil, 2010.

\begin{tabular}{lccccc}
\hline & $\begin{array}{c}\text { Total } \\
\text { Pesquisado- } \\
\text { res }\end{array}$ & $\begin{array}{c}\text { \% de Pesqui- } \\
\text { sadores em } \\
\text { relação ao } \\
\text { total }\end{array}$ & $\begin{array}{c}\text { \% de douto- } \\
\text { res em rela- } \\
\text { cão ao total } \\
\text { de pesquisa- } \\
\text { dores }\end{array}$ & $\begin{array}{c}\text { Total } \\
\text { artigos }\end{array}$ & $\begin{array}{c}\text { \% de artigos } \\
\text { em relação } \\
\text { ao total }\end{array}$ \\
\hline $\begin{array}{l}\text { Ciências } \\
\text { Agrárias }\end{array}$ & 15.269 & $10 \%$ & $77 \%$ & 113.928 & $16 \%$ \\
$\begin{array}{l}\text { Ciências } \\
\text { Biológicas }\end{array}$ & 16.033 & $11 \%$ & $82 \%$ & 128.045 & $18 \%$ \\
$\begin{array}{l}\text { Ciências da } \\
\begin{array}{l}\text { Saúde } \\
\text { Ciências }\end{array}\end{array}$ & 25.445 & $17 \%$ & $62 \%$ & 181.003 & $25 \%$ \\
$\begin{array}{l}\text { Exatas e da } \\
\text { Terra }\end{array}$ & 14.621 & $10 \%$ & $81 \%$ & 91.422 & $13 \%$ \\
$\begin{array}{l}\text { Ciências } \\
\text { Humanas }\end{array}$ & 30.378 & $21 \%$ & $56 \%$ & 74.863 & $10 \%$ \\
$\begin{array}{l}\text { Ciências } \\
\begin{array}{l}\text { Sociais } \\
\text { Aplicadas }\end{array}\end{array}$ & 18.579 & $13 \%$ & $52 \%$ & 49.410 & $7 \%$ \\
$\begin{array}{l}\text { Engenharias } \\
\text { Linguistica, }\end{array}$ & 18.453 & $12 \%$ & $70 \%$ & 67.837 & $9 \%$ \\
$\begin{array}{l}\text { Letras e } \\
\text { Artes }\end{array}$ & 8.860 & $6 \%$ & $62 \%$ & 19.274 & $3 \%$ \\
\hline $\begin{array}{l}\text { Total } \\
\text { Total }\end{array}$ & 147.638 & $100 \%$ & $66 \%$ & 725.782 & $100 \%$ \\
\hline
\end{tabular}

Fonte: Elaboração própria a partir dos dados do Diretório de Grupos de Pesquisa do CNPq.

Nota: Os valores apresentados referem-se ao somatório de pesquisadores e artigos de todas as instituições cadastradas no Diretório de Grupos de Pesquisa. Artigos referem-se ao somatório das publicações nacionais e internacionais em jornais e periódicos indexados.

Contudo, uma investigação dentro da grande área de engenharias, aponta que dentre os 18.579 pesquisadores, 17,6\% deles se encontram na área Engenharia Elétrica, 11,4\% em Engenharia Civil e 10,4\% em Engenharia Mecânica, áreas importantes, mas tradicionais. Apenas 3\% dos pesquisadores estão em Engenharia Biomédica e 1\% em Engenharia Aeroespacial (TAB. 4), 
áreas vinculadas aos setores de desenvolvimento estratégico.

Tabela 4: Percentual de pesquisadores por área de conhecimento em relação a grande área de Engenharia, Brasil, 2010.

\begin{tabular}{lclc}
\hline \multicolumn{1}{c}{ Grande área de Engenharia } & $\begin{array}{c}\text { Pesqui- } \\
\text { sadores } \\
\text { (\%) }\end{array}$ & Grande área de Engenharia & $\begin{array}{c}\text { Pesqui- } \\
\text { sadores } \\
\text { (\%) }\end{array}$ \\
\hline Engenharia Elétrica & $17,60 \%$ & Engenharia Agrícola & $5,00 \%$ \\
Engenharia Civil & $11,40 \%$ & Engenharia de Pesca & $4,60 \%$ \\
Engenharia Mecânica & $10,40 \%$ & Engenharia Biomédica & $3,00 \%$ \\
Engenharia de Materiais e & $9,90 \%$ & Engenharia Nuclear & $2,50 \%$ \\
Metalúrgica & $9,70 \%$ & Engenharia de Transportes & $1,70 \%$ \\
Engenharia de Produção & $8,20 \%$ & Engenharia de Minas & $1,00 \%$ \\
Engenharia Química & $6,90 \%$ & Engenharia Aeroespacial & $1,00 \%$ \\
Engenharia Sanitária & $6,80 \%$ & Engenharia Naval e Oceânica & $0,30 \%$ \\
Engenharia Florestal & &
\end{tabular}

Fonte: Elaboração própria a partir dos dados do Diretório de Grupos de Pesquisa do CNPq.

Os dados apresentados apontam, portanto, para um desalinhamento entre as áreas de pesquisa e a formação de pesquisadores e os setores de desenvolvimento estratégico nacional. A falta de pessoal qualificado, seja para a geração interna de conhecimento nas empresas ou para o estabelecimento de cooperação com outros agentes do SNI, é um gargalo estrutural, relevante, que tem sido ignorado pela política de CT\&I.

De acordo com Gusso e Nascimento (2011) grande parte das conclusões de cursos de graduação no Brasil ocorre nas áreas de humanas e sociais aplicadas, sendo ainda minoritárias as conclusões nas chamadas áreas de hard science (exatas, biológicas, computação e engenharias). No entanto, os autores não analisam a produção de conhecimento nem a alocação de recursos (humanos e financeiros) por área, o que será feito a seguir.

De fato nem todas as pesquisas conduzidas pelas IES brasileiras são destinadas a setores estratégicos para o desenvolvimento industrial e econômico do país. Analisando os grupos de pesquisa do Conselho Nacional de Desenvolvimento Científico e Tecnológico ( $\mathrm{CNPq}$ ), conforme a classificação proposta pela CAPES, é possível constatar que a maior parcela de grupos de pesquisa registrados no CNPq pertence às Ciências Humanas (19\%), seguido por Ciências Exatas e da Terra (17\%) e Engenharias (13\%). Se examinarmos a distribuição de pesquisadores brasileiros ${ }^{14}$ por área de conhecimento, conferese que a maior concentração ocorre também em Ciências Humanas (19,56\%). A segunda área com maior concentração de pesquisadores é Ciências da Saúde (17,97\%). (TAB. 5).

Tabela 5: Distribuição dos grupos de pesquisa, pesquisadores, artigos

\footnotetext{
14 Estamos cientes que é questionável adotar o número de pesquisadores registrados no Diretório dos Grupos de Pesquisa do CNPq como proxy da alocação de recursos humanos em C\&T nas universidades, uma vez que é grande o número de pesquisadores não vinculados a grupos de pesquisa ou grupos de pesquisa não registrados no diretório, bem como o fato de um mesmo pesquisador participar de diversos grupos de pesquisa simultaneamente, no entanto, não existe outra base de dados de onde podemos obter essas informações. Por isso, optou-se, mesmo sabendo dessa deficiência, em utilizar o DGP/CNPq.
} 
científicos, programas de pós-graduação, segundo áreas do conhecimento das IES brasileiras, \%, 2008.

\begin{tabular}{|c|c|c|c|c|c|c|}
\hline & $\begin{array}{l}\text { Grupos de } \\
\text { Pesquisa }\end{array}$ & $\begin{array}{l}\text { Pesquisado- } \\
\text { res }\end{array}$ & $\begin{array}{l}\text { Produção } \\
\text { Bibliográ- } \\
\text { fica }\end{array}$ & $\begin{array}{l}\text { Produção } \\
\text { Tecnológica }\end{array}$ & $\begin{array}{l}\text { Programas } \\
\text { de pós- } \\
\text { graduação* }\end{array}$ & $\begin{array}{c}\text { Estudantes } \\
\text { na pós- } \\
\text { graduação* }\end{array}$ \\
\hline $\begin{array}{l}\text { Ciências } \\
\text { Agrárias }\end{array}$ & 9,55 & 10,37 & 15,72 & 4,02 & 10,98 & 9,44 \\
\hline $\begin{array}{l}\text { Ciências } \\
\text { Biológicas }\end{array}$ & 11,83 & 11,33 & 18,14 & 21,17 & 8,1 & 7,62 \\
\hline $\begin{array}{l}\text { Ciências da } \\
\text { Saúde }\end{array}$ & 17,38 & 17,97 & 24,69 & 18,09 & 16,86 & 14,43 \\
\hline $\begin{array}{l}\text { Ciências Exatas } \\
\text { e da Terra }\end{array}$ & 11,03 & 10,03 & 13,23 & 18,62 & 10,09 & 9,63 \\
\hline Humanas & 18,51 & 19,56 & 10,05 & 3,98 & 14,25 & 16,99 \\
\hline $\begin{array}{l}\text { Sociais } \\
\text { Aplicadas }\end{array}$ & 12,08 & 12,23 & 6,5 & 2,54 & 12,69 & 12,64 \\
\hline Engenharias & 13,28 & 12,88 & 8,96 & 30,8 & 11,02 & 14,83 \\
\hline $\begin{array}{l}\text { Lingüística, } \\
\text { Letras e Artes }\end{array}$ & 6,35 & 5,63 & 2,7 & 0,78 & 5,41 & 6,45 \\
\hline Multidisciplinar & $\mathrm{n} / \mathrm{a}$ & $\mathrm{n} / \mathrm{a}$ & $\mathrm{n} / \mathrm{a}$ & $\mathrm{n} / \mathrm{a}$ & 10,59 & 7,98 \\
\hline Total & 100 & 100 & 100 & 100 & 100 & 100 \\
\hline \multicolumn{7}{|c|}{$\begin{array}{l}\text { Fonte: Elaboração própria. Dados do Diretório de Grupos de Pesquisa do Conselho Nacional } \\
\text { para Desenvolvimento Científico e Tecnológico (CNPq). *Dados do GeoCapes/CAPES). Nota: } \\
\text { Aqui nós consideramos todas as IES públicas e privadas existentes no Brasil. Nota: Programas } \\
\text { de pós-graduação referem-se ao número de programas de mestrado e doutorado. Produção } \\
\text { bibliográfica refere-se aos artigos publicados nacional e internacionalmente em publicações } \\
\text { indexadas; produção tecnológica refere-se à soma da produção de software e produtos } \\
\text { tecnológicos com patente registrada. }\end{array}$} \\
\hline
\end{tabular}

Ao observar a publicação de artigos científicos, encontra-se que $24,69 \%$ são publicações da área de Ciências da Saúde. As publicações na área de Engenharia representam apenas 9\% do total. (TAB. 5).

É importante reconhecer que no Brasil existe uma expressiva concentração de recursos humanos em Ciências Humanas, Sociais Aplicadas e também Lingüística, Artes e Letras (que juntas respondem por quase 37\% dos pesquisadores), enquanto apenas $13 \%$ dos pesquisadores são alocados em Engenharia. Tal distorção pode estar relacionada ao grande número de IES que oferecem diversos cursos em áreas como Ciências Humanas e Sociais Aplicadas, por serem cursos que demandam investimentos relativamente baixos em infraestrutura e equipamentos, como é o caso de Administração, Direito, entre outros (Mello et al., 2009). Quando observamos as universidades federais mais as USP, UNESP e UNICAMP, o número de pesquisadores alocados em Humanas, Sociais Aplicadas e Linguística, Letras e Artes chega a 35\% do total (FIG. 1). 
Figura 1: Distribuição dos Pesquisadores por área do conhecimento Universidades federais mais USP, UNESP e UNICAMP - Brasil - 2008.

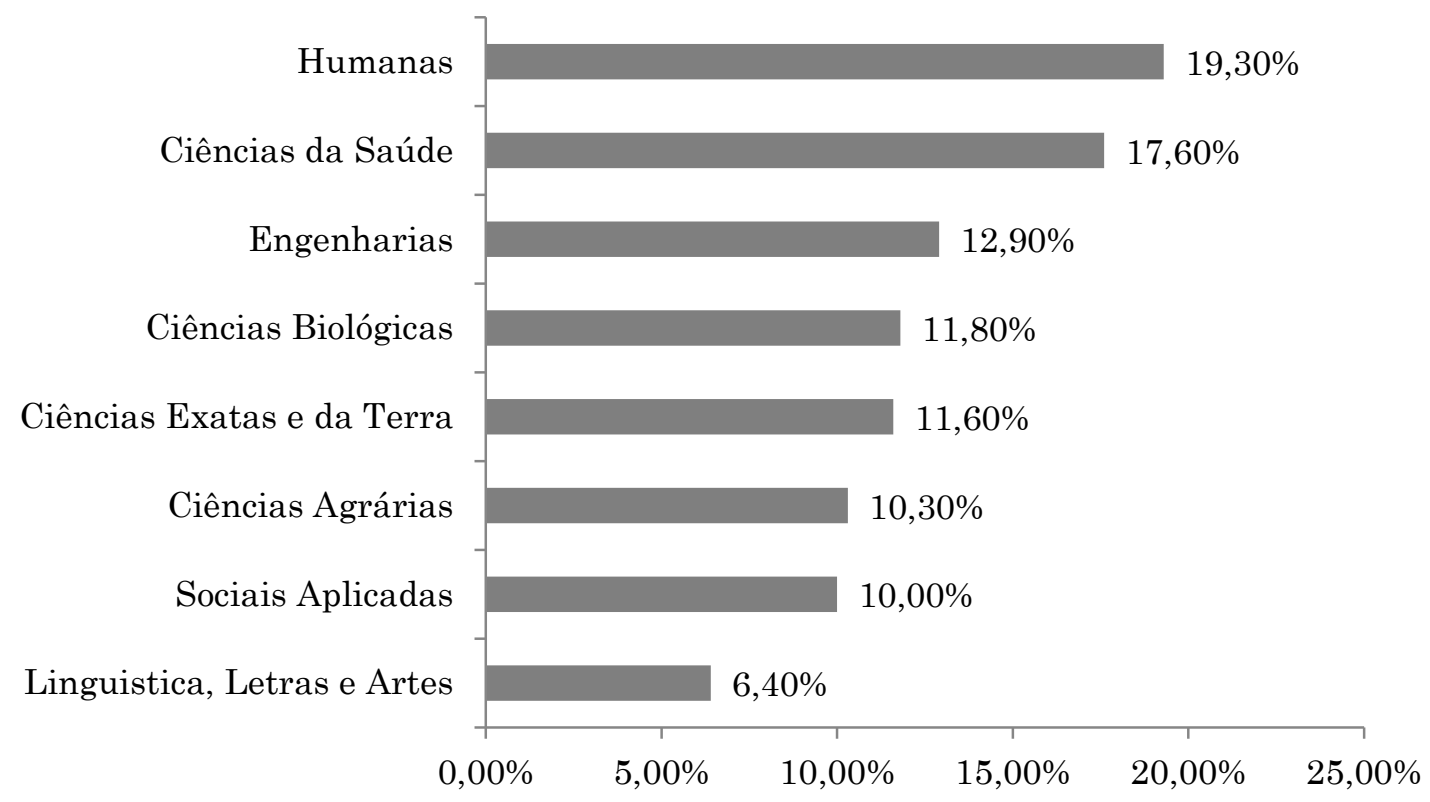

Fonte: Elaboração própria. Dados do Diretório de Grupos de Pesquisa do CNPq.

Uma peculiaridade da educação superior no Brasil é que as IES públicas são o maior suporte do sistema de pesquisa do país, especialmente no que tange aos programas de pós-graduação dessas instituições. Em 2008, a CAPES tinha 2.718 programas de pós-graduação registrados no país, sendo aproximadamente $32 \%$ deles nas áreas de Humanas, Sociais Aplicadas e Linguística, Letras e Artes. Cerca de 46.000 estudantes foram matriculados em programas de pósgraduação nas IES brasileiras, no mesmo período: 36\% deles matricularam-se em Humanas, Sociais Aplicadas ou Linguística, Letras e Artes. Nos próximos anos, disponibilizará no mercado de trabalho cerca de 54 mil mestres/doutores das áreas acima referidas. Mais que o dobro do número de pós-graduados que serão formados em cursos de Engenharia.

\subsection{Investimentos públicos nas IES brasileiras}

Agências federais como a CAPES e o CNPq realizam o fomento à pesquisa, no Brasil, através de recursos não reembolsáveis. As agências estaduais possuem o mesmo objetivo, sendo que a de maior destaque entre elas é a Fundação de Amparo à Pesquisa do Estado de São Paulo (FAPESP).

Ao observar os recursos não reembolsáveis destinados à pesquisa pela FAPESP, nota-se que houve um crescimento real de 22,32\%, entre 2006 e 2010. Em 2010, os investimentos da FAPESP em pesquisa nas IES localizadas no Estado de São Paulo chegaram a US\$ 443,1 milhões e 11,06\% destes foram direcionados para pesquisas em inovação tecnológica. Ao considerar os investimentos da CAPES, houve crescimento real de 30,9\%, entre 2006 e 2008. 
Em 2008, o investimento chegou a US\$ 447,2 milhões. Entre 2006 e 2010, houve crescimento real de $46,02 \%$ dos investimentos do CNPq em pesquisas de IES brasileiras. (TAB. 4).

A distribuição dos recursos para pesquisa nas IES brasileiras mostra que somente $10 \%$ deste financiamento (somente recursos do $\mathrm{CNPq}$ ) vai para áreas do conhecimento sem relação direta com setores estratégicos da PITCE apresentados anteriormente, como Humanas, Sociais Aplicadas e Linguística, Letras e Artes.

Em 2008, Agronomia, Medicina, engenharia, Física, Química e Fármacos, e Ciências da Computação receberam juntas 43,3\% dos US\$ 635,7 milhões destinados a projetos de pesquisa, eventos e pós-graduação (no Brasil e no exterior) pelo CNPq. (FIG. 2).

Tabela 6: Recursos financeiros para pesquisa, CNPq, CAPES e FAPESP, 2006-2010, US\$ milhões

\begin{tabular}{crcc}
\hline & CNPq & CAPES & FAPESP \\
\hline 2006 & 408,6 & 260,3 & 239,8 \\
2007 & 617,5 & 308,7 & 282,1 \\
2008 & 635,7 & 447,2 & 347,7 \\
2009 & 665,2 & $\mathrm{n} / \mathrm{a}$ & 340,2 \\
2010 & 900 & $\mathrm{n} / \mathrm{a}$ & 443,2 \\
2006-2008 Crescimento real & $20,60 \%$ & $30,90 \%$ & $10,50 \%$ \\
2006-2010 Crescimento real & $46,02 \%$ & $\mathrm{n} / \mathrm{a}$ & $22,32 \%$ \\
\hline
\end{tabular}

Nota: Para calcular o crescimento real, usamos a série de inflação do IPCA. Os valores foram deflacionados em Reais $(\mathrm{R} \$)$. 
Figura 2: Distribuição dos investimentos do CNPq em pesquisa por áreas do conhecimento específicas, IES brasileiras, 2008.

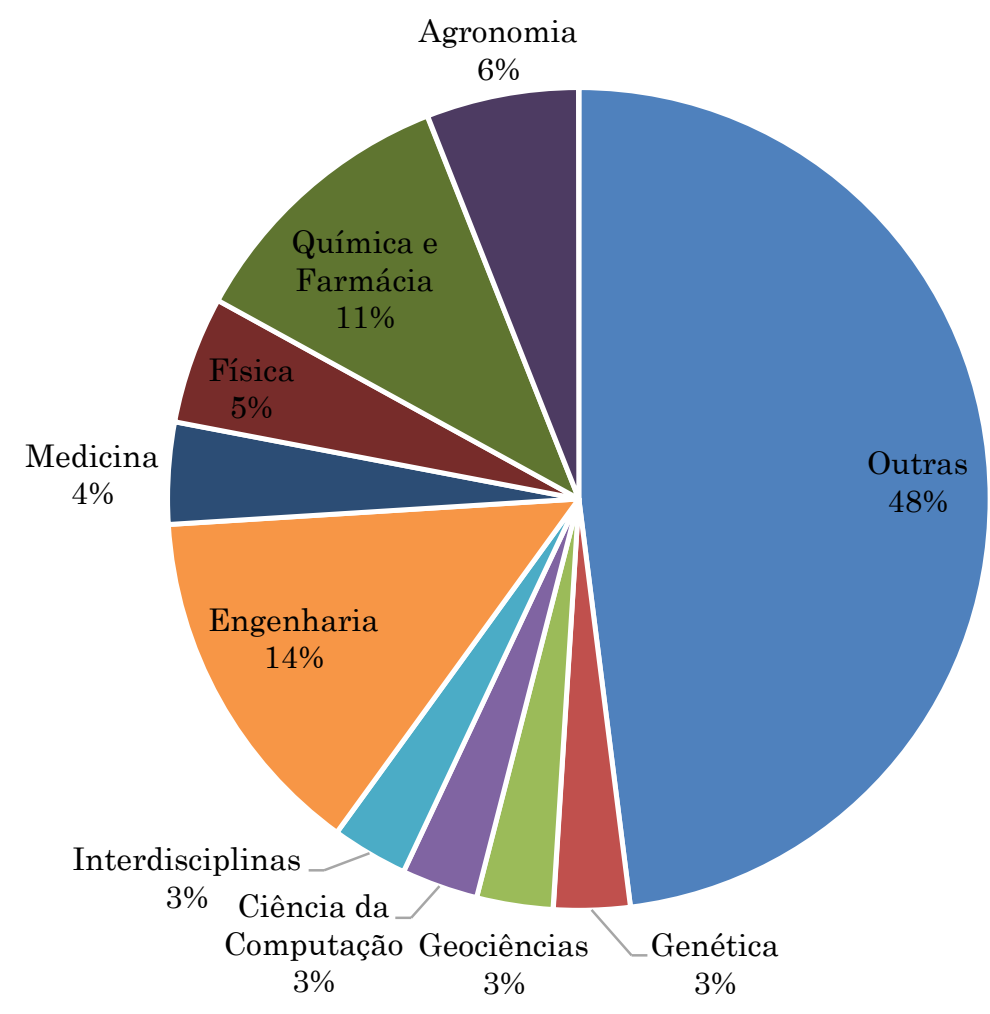

Fonte: Chiarini e Vieira (2012, p. 129).

Estas três agências (CAPES, FAPESP e CNPq) são fundamentais no suporte à pesquisa e produção de conhecimento das IES brasileiras. Neste artigo, entretanto, tomamos como base de análise apenas os investimentos realizados pelo $\mathrm{CNPq}$ no fomento a projetos de pesquisa ${ }^{15}$.

Em 2008, dos US\$ 635,7 milhões investidos pelo CNPq, US\$ 195 milhões foram para projetos de pesquisa (64\% destes de universidades federais mais USP, UNESP e UNICAMP). Dentro destes 64\%, 14,09\% foram alocados na USP (FIG. 3).

Ao contrário do que acontece com a alocação de humanos, que se concentra no âmbito das ciências humanas, ciências sociais aplicadas elingüística, artes e letras (que em conjunto, representam quase $37 \%$ dos pesquisadores), o Brasil parece alocar recursos financeiros para a pesquisa principalmente em Ciências Biológicas (21,7\%) e Engenharia (15,2\%), o que parece se alinhar com os setores estratégicos para o país, conforme a PITCE (TAB. 6).

\footnotetext{
15 Duas razões justificam tal escolha: a primeira razão é de ordem institucional: a opção de analisar apenas esta agência de suporte à pesquisa deve-se a sua finalidade de promover e estimular o desenvolvimento científico e tecnológico do país e contribuir para a formulação de políticas nacionais de ciência e tecnologia, sendo vinculada ao Ministério da Ciência e Tecnologia. Além disso, trata-se da principal fonte de recursos não-reembolsáveis destinados à pesquisa, conforme identificado na TAB. 3. A segunda razão é determinante para nosso trabalho de pesquisa: é muito difícil encontrar dados segmentados por IES sobre investimentos de outras instituições de apoio a pesquisa. O mesmo vale para todos os outros dados investigados neste artigo. Sendo assim, optamos por basear a pesquisa em informações do CNPq.
} 
Figura 3: Investimento do CNPq em projetos de pesquisa, em universidades selecionadas, \%, 2008.

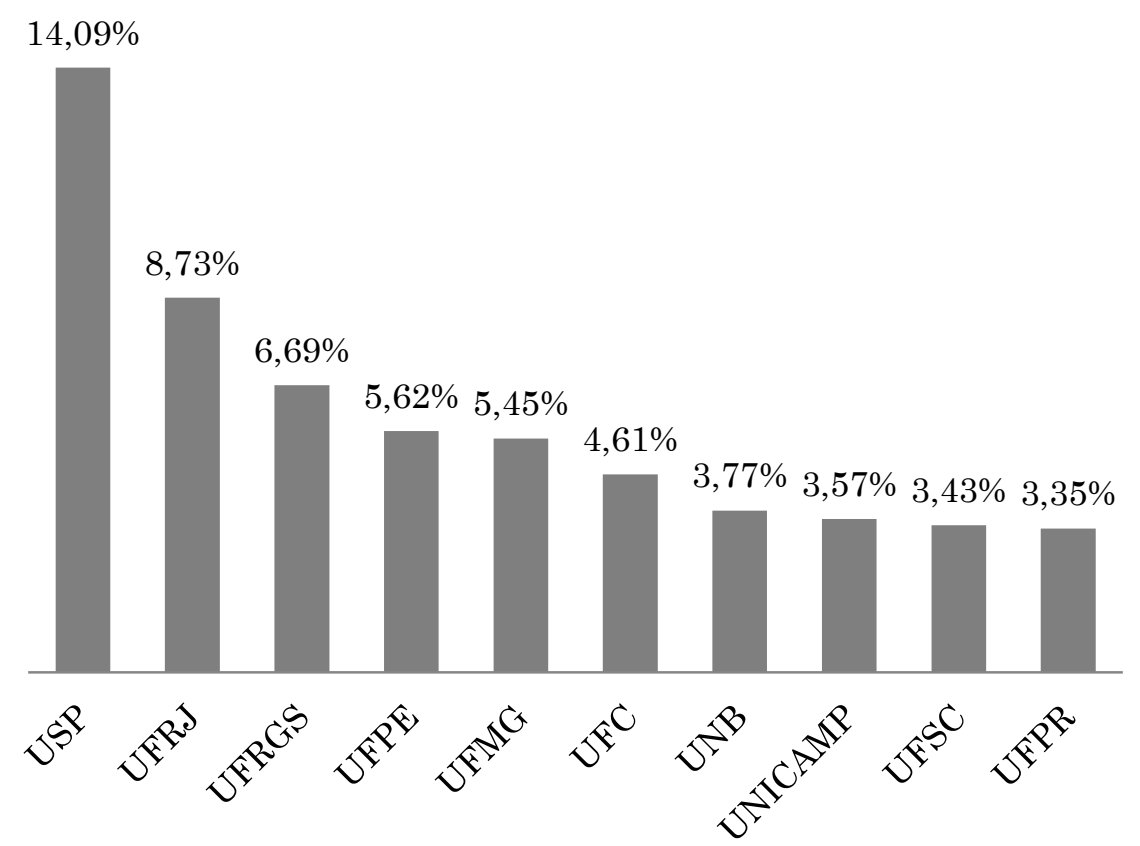

Fonte: Chiarini e Vieira (2012, p. 129).

Tabela 7: Distribuição de recursos financeiros por área de conhecimento, 2008.

\begin{tabular}{lcr}
\hline & US\$ & \% \\
\hline Ciências Biológicas & $42.428 .019,00$ & 21,7 \\
Engenharias & $29.775 .138,00$ & 15,2 \\
Ciências Exatas e da Terra & $29.284 .522,00$ & 15 \\
Ciências Agrícolas & $29.261 .384,00$ & 15 \\
Ciências da Saúde & $28.622 .003,00$ & 14,7 \\
Ciências Humanas & $9.682 .300,00$ & 5 \\
Ciências Sociais Aplicadas & $6.594 .161,00$ & 3,4 \\
Linguistica, Artes e Literatura & $1.382 .026,00$ & 0,7 \\
Outros & $18.262 .863,00$ & 9,4 \\
\hline Total & $195.292 .416,00$ & 100 \\
\hline
\end{tabular}

Fonte: Chiarini e Vieira (2012, p. 130).

Assim, se o Brasil tem uma defasagem em inovação, isto pode ser devido à falta de recursos humanos em áreas estratégicas, e não à má alocação dos gastos públicos no financiamento à pesquisa. 


\section{Considerações Finais}

Neste trabalho, procuramos realizar uma breve caracterização do sistema universitário brasileiro e das políticas industriais e de inovação recentes. O Estado teve e ainda tem participação importante no fomento à formação de recursos humanos altamente qualificados, bem como na produção de conhecimento, através das universidades públicas, sendo essas as principais instituições responsáveis pela produção de novos conhecimentos no Brasil.

No governo FHC (1995-2002) a expansão do acesso ao ensino superior no Brasil, iniciado em meados de 1990, gerou, um efeito de democratização contrário, pois se ampliaram as IES privadas e ocasionou uma concentração nos grandes centros urbanos (Pereira e Silva, 2010). Por outro lado, o governo Lula (2003-2010) retomou o papel do Estado como ator indutor de políticas para a expansão universitária no país, criando políticas como o Programa Universidade para Todos (ProUni), a Universidade Aberta do Brasil (UAB) e o Programa de Apoio ao Plano de Reestruturação e Expansão das Universidades Federais (Reuni), além do aumento da oferta do crédito educativo a partir do Fundo de Financiamento ao Estudante do Ensino Superior (FIES) ${ }^{16}$, os quais integram uma macro-política cobrindo o ensino básico, superior e profissional e tecnológico, o Plano de Desenvolvimento da Educação (PED). Isso corrobora que o Estado brasileiro tem realizado esforços no sentido de ampliar o acesso à educação superior no país e o que tudo indica é que o governo Rousseff manterá os feitos do governo anterior.

Consideramos que tais esforços são válidos para a qualificação da mãode-obra e, mais do que isso, tais esforços podem contribuir para potencializar a capacidade de produção de CT\&I no país, caso estejam comprometidos ou integrados à política de CT\&I brasileira. Ressalva-se que ampliar as vagas não garante a qualidade dos profissionais que encontrarão no mercado de trabalho e não garante também que estarão formando profissionais condizentes com as áreas estratégicas e nem ao menos que haverá um incentivo à produção de novos conhecimentos científicos e tecnológicos voltados às áreas estratégicas. É preciso políticas direcionadas de incentivo à pesquisa e à formação de mão-deobra altamente qualificada condizentes com as políticas de CT\&I.

Através da análise empírica, nota-se que as principais áreas de conhecimento em que o Brasil aloca recursos financeiros para pesquisa científica são: ciências biológicas e engenharia, o que vai de encontro às definições das políticas de CT\&I do país, no que diz respeito aos setores estratégicos ao desenvolvimento. No que se refere à alocação de recursos humanos em pesquisa, observou-se que, no Brasil, há uma concentração significativa de recursos humanos em pesquisas na área de ciências humanas, ciências sociais aplicadas e lingüística, artes e letras (que em conjunto representam quase 37\%

16 Para maiores detalhes sobre as políticas de ensino superior nos governos FHC e Lula ver: PEREIRA, T. I.; SILVA, L. F. S. C.. As políticas públicas do ensino superior no governo Lula: expansão ou democratização? Revista Debates, Porto Alegre, v.4, n.2, p. 10-31, jul.-dez. 2010; e CARVALHO, C. H. A.. Política para o ensino superior no Brasil (1995-2006): ruptura e continuidade nas relações entre público e privado. In: Anais da XXIX Reunião da ANPEd, Caxambu, 2006. 
dos pesquisadores), enquanto apenas $13 \%$ dos pesquisadores estão atribuídos às pesquisas em engenharia. Pesquisa recente do Instituto de Pesquisa Econômica Aplicada (IPEA) demonstra que, embora nos anos mais recentes, não só a procura por cursos de engenharia, como também sua oferta, vêm mostrando aceleração, é necessário mobilizar um sistema de educação superior significativo para dar conta das demandas emergentes e é preciso formação de agentes de inovação que conectem a produção de conhecimento com o avanço das capacidades tecnológicas e competitivas do sistema produtivo (Guso; Nascimento, 2011).

É possível refletir que o Brasil pode não estar produzindo quantidade relevante de recursos humanos necessários para competir nos mercados mundiais altamente tecnológicos. Isso é preocupante, uma vez que o país precisa de capital humano qualificado em áreas tecnológicas, para que possa realizar o catch-up com economias mais avançadas. Além disso, mão-de-obra em áreas como saúde e educação também são fundamentais no contexto brasileiro, a fim de atender às necessidades estruturais, que são pontos de estrangulamento econômico e social no país.

Conforme proposto por Arocena e Sutz (2010), há diferença entre o aprender estudando (learning by studying) e o aprender resolvendo (learning bu solving). Ao passo que o primeiro está relacionadao com a oferta de conhecimento, o segundo decorre da participação em atividades que demandam conhecimento, incluindo a solução de problemas. Muitos individuos, em países avançados, dispõem de oportunidade para aprender estudando e resolvendo. Por sua vez, os países do Sul caracterizam-se pelas fraturas de aprendizado ("learning divides"), uma vez que é mais dificil fomentar o aprender resolvendo e que as políticas de inovação tendem a focar na oferta do conhecimento (fomento ao learning by studying). $\mathrm{O}$ que os dados apresentados neste artigo apontam, é para um descompasso que se inicia no learning by studying.

A partir das evidências encontradas neste trabalho, percebe-se que há uma distorção entre a formação de recursos humanos de nível superior e as áreas estratégicas para o país, propostas pela PITCE e pelo Plano Brasil Maior. Dito isto, propõe-se aqui a integração entre as políticas educacionais de ensino superior e as políticas brasileiras de CT\&I. Assim, o que se defende aqui é a atuação das universidades como atores estratégicos não apenas na política educacional, mas também na política de CT\&I. Dentro de tal proposta, abre-se uma agenda de pesquisa no sentido de propor e avaliar medidas que possam levar a tal integração. 


\section{Referências}

Albuquerque, E. M. (2004). Science and technology systems in Less Developed countries: identifying a threshold level and focusing in the cases of India and Brazil. In: Moed. H.; Glänzel. W.; Schmoch. U. (Ed.). Handbook of quantitative science and technology research: the use of publication and patent statistics in studies of S\&T systems. Dordrecht: Kluwer Academic Publishers.

Albuquerque, E. M.; Silva, L. A..; Póvoa. L. M. C. (2005). Diferenciação intersetorial na interação entre empresas e universidades no Brasil. São Paulo em Perspectiva. São Paulo. v. 19. n. 1. p. 95-104.

Albuquerque, E. M.; Britto, G.; Camargo, O. S.; Kruss, G. (2011). Global interactions between firms and universities: global innovation networks as first steps towards a Global Innovation System. UFMG/Cedeplar. Texto para Discussão 419,

Almeida, J. G. (2011). Alcance e lacunas da nova política industrial. Texto para Discussão. IE/UNICAMP, n. 196, out. de 2011.

Almeida, M. (2011). O novo estado desenvolvimentista e o governo Lula. Economia \& Tecnologia, ano 7, volume especial.

Arocena, R.; Sutz, J. (2001). Changing knowledge production and Latin American universities. Research Policy. Vol. 30.

Arocena, R.; Sutz, J. (2003). Knowledge, innovation and learning: systems and policies in the north and in the south. In: Cassiolato, J. E.; Lastres, H. M. M.; Maciel, M. L. (eds.) Systems of Innovation and Development - Evidence from Brazil, Edward Elgar.

Arocena, R.; Sutz, J. (2010) Weak knowledge demand in the South: learning divides and innovation policy. Science and Public Policy, v.37, n.8, outubro, p.571-582.

Campanário, M. A.; Silva, M. M.; Costa; T. R. (2005). Política Industrial, Tecnológica e de Comércio Exterior (PITCE): análise de fundamentos e arranjos institucionais. In: XI Seminário Latino-Iberoamericano de Gestión Tecnologica. Salvador.

Chiarini, T.; Vieira, K. P. (2011). Alinhamento das atividades de pesquisa científica e tecnológica realizadas pelas IES federais de MG e as diretrizes da Política Industrial e de Comércio Exterior. Revista Brasileira de Inovação (Unicamp. Impresso).

Chiarini, T.; Vieira, K. P. (2012). Universidades como produtoras de conhecimento para o desenvolvimento econômico: sistema superior de ensino e as políticas de CT\&I. Revista Brasileira de Economia, v. 66, n. 1, p. 117-132.

Edquist, C. (2005). Systems of Innovation - Perspectives and Challenges. IN: Fagerberg, J.; Mowery, D.; Nelson, R., R. The Oxford Handbook of Innovation. Oxford: Oxford University Press.

Fernandes, A.C; Campello De Souza, B.; Stamford Da Silva, A.; Suzigan, W.; Albuquerque, E. (2010). Academy-industry links in Brazil: evidence about channels and benefits for firms and researchers, Science and Public Policy, 37(7), August 2010. 
Freeman, C. (1992 ). Formal scientific and technical institutions in the NSI. In: Lundvall, B. A.. National Systems of Innovation. London: Pinter Publishers.

Gusso, D. A.; Nascimento, P. A. M. M. (2011). Contexto e dimensionamento da formação de pessoal técnico-científico e de engenheiros. Radar, Brasília: Ipea, $\mathrm{n}$. 12, fev. 2011.

Kapur, D.; Mehta, P. B. (2004). Indian high education reform: from half-backed socialism to half-backed capitalism. Working Papers, Center for International Development at Harvard University.

Koeller, P.(2007). O papel do estado e a política de inovação. Rede Sist., Universidade Federal do Rio de Janeiro, Brasil.

Lundvall, B.A.; Christensen, J. L. (1999). Extending and deepening the analysis of innovation system: with empirical illustrations from the DISCO-project, DRUDI Working Paper No. 99-12, Outubro de 1999.

Maculan, A. M.; Mello, J. M. C. (2009 ). University start-ups for breaking lock-ins of the Brazilian economy. Science and Public Policy. Vol. 36. n. 2.

Meyer- Kramer, F.; Schmoch, U. (1998). Science-based technologies: universityindustry interactions in four fields. Research Policy, v.27, n.8, p. 835-851, December.

Mazzoleni, R.; Nelson, R. (2006). The roles of research at universities and public labs in economic catch up. Laboratory of Economics and Management Sant'Anna School of Advanced Studies, Pisa, Italy.

Mello,J. M. C.; Maculan, A. M.; Renault, T. (2009). Brazilian Universities and their Contribution to Innovation and Development. In: Bo Goransson; Claes Brundenius. (Org.). Developing Universities: The Changing Role of Academic Institutions in Development. Londres: Routledge/IDRC. 2009. v. . p. 1-25.

Nelson, R.. Capitalism as an engine of progress (1990). Research Policy, v. 19, p. 193214.

Nowotny, H., et al. (2001). Re-Thinking Science: Knowledge and the Public in an Age of Uncertainty. Polity Press, Cambridge.

OECD, Organisation for Economic Co-operation and Development. (2010). Education at a Glance. <http://www.oecd.org/dataoecd/45/39/45926093.pdf> acesso em $11 \mathrm{de}$ julho de 2011.

Oliveira, F (2003). Crítica à razão dualista/O ornitorrinco. São Paulo: Boitempo Editorial.

Rapini, M. S.; Chiarini, T.; Bittencourt, P. F. (2013). Innovation System and development in Latin America: University-Industry interactions in Brazil. In: XVIII Encontro Nacional de Economia Política, 2013, Belo Horizonte. Anais do XVIII Encontro Nacional de Economia Política.

Rodrígues, A.; et al. ( 2008 ) (ed). Knowledge and innovation for competitiveness in Brazil. The International Bank for Reconstruction and Development/The World Bank. Washington. 268p.

RS, Royal Society. (2011) Knowledge. networks and nations: global scientific collaboration in the $21^{\text {st }}$ century. London: RS Policy document 03/2011. 
Rosenberg, N., Nelson, R. R. (1994). American universities and technical advance in industry. Research Policy, 23, 323-348.

Rosenberg, N.(1976). Perspectives on Technology, Cambridge: Cambridge University.

Salerno, M. S. (2004). A política industrial, tecnológica e de comércio exterior do governo federal. Parcerias Estratégicas, n.19, dez.

Suzigan, W.; Albuquerque, E. M. (2011). The underestimated role of universities for development. Brazilian Journal of Political Economy, v. 31, n. 1, p.3-30. Jan./ Mar 2011.

Suzigan, W.; Albuquerque, E.; Garcia, R; Rapini, M.S. (2009). University and industry linkages in Brazil: some preliminary and descriptive results. Seoul Journal of Economics, v.22, n.4, Winter, 2009.

Suzigan, W.; Rapini, M. S.; Albuquerque; E. M. (2011). A changing role for universities in the periphery. UFMG/Cedeplar. Texto para Discussão 420.

UNESCO, United Nations Educational. (2010). Scientific and Cultural Organization. Global education digest 2010: comparing education statistics across the world. Disponível em: <http://unesdoc.unesco.org/images/0018/001894/189433e.pdf>, acesso em: 11 de julho de 2011.

WB, World Bank (2011). Higher education for growth through skills and research.

Webster, A. J. (1994). International evaluation of academic-industry relations: contexts and analysis. Science and Public Policy, V. 21, N. 2, p. 72-78, april 1994. 